\title{
Hernia diafragmática derecha complicada tras hepatectomía. Presentación de un cuadro oclusivo
}

\author{
Neith Ortega, Néstor Betancort, Mercedes Cabrera, Javier Larrea, Juan Ramón Hernández \\ Cirugia general. Hospital Universitario Insular de Gran Canaria.
}

Acta Gastroenterol Latinoam 2020;50(2):144-146

Recibido: 13/07/2018 / Aceptado: 23/04/2020 / Publicado online: 29/06/2020

\section{Resumen}

La hernia diafragmática traumática constituye una forma infrecuente de afección. Presentamos el caso de una hernia diafragmática derecha que se complicó a causa de una hepatectomía.

Palabras claves. Hernia diafragmática traumática, cirugia hepática, oclusión intestinal.

\section{Right diaphragmatic hernia complicated after right hepatectomy. Presentation as an intestinal occlusion}

\section{Summary}

Traumatic diaphragmatic hernia is an infrequent form of diaphragmatic disease. We present the case of a complicated right diaphragmatic hernia after right hepatectomy.

Key words. Traumatic diaphragmatic hernia, liver surgery, intestinal occlusion.

Correspondencia: Neith Ortega

Avenida Maritima del Sur, s/n (C.P.: 35016). Las Palmas de Gran

Canaria. Las Palmas, España

Tel.: (34) 928 444000/ (34) 690651747

Correo electrónico: neithortega@gmail.com

\section{Introducción}

La hernia diafragmática traumática constituye una forma infrecuente de afecciónen la actualidad. ${ }^{1-3}$

Las lesiones iatrogénicas sobre el diafragma son infrecuentes y pueden estar asociadas con la ablación por la radiofrecuencia o una cirugía abdominal sobre órganos adyacentes. ${ }^{4,5}$

Se presenta el caso de un paciente con un cuadro de oclusión intestinal secundario que desencadena una hernia diafragmática derecha a causa de una cirugía hepática.

\section{Caso clínico}

Varón de 59 años de edad con antecedentes de HTA y exfumador. Fue intervenido por una neoplasia de colon (pT2N0). Se le realizó una hemicolectomía derecha. A causa de las metástasis hepáticas, recibió una quimioterapia adyuvante. Tiempo después se le realizó una cirugía por la metástasis en la cual se objetivó una infiltración diafragmática, por lo que se efectuó una hepatectomía derecha y segmentectomía S-I con la resección parcial de la vena cava.

A los cinco meses de la intervención, el paciente acude a urgencias con un cuadro de dolor abdominal y vómitos de 72 horas de evolución, sin referir disnea ni otra sintomatología acompañante. En el momento de la exploración se encontraba hemodinámicamente estable y eupneico, con un abdomen doloroso y distendido, pero sin peritonismo. En urgencias se le realiza un análisis de sangre sin hallazgos a destacar, pero en la tomografía abdominal computarizada (TAC) de tórax/abdomen se observó una hernia diafragmática derecha con un estrangulamiento de las asas intestinales (Figuras 1 y 2). 
Figura 1 y 2. Imágenes del TAC toracoabdominal donde se visualiza una hernia diafragmática derecha complicada con el estrangulamiento de las asas intestinales.

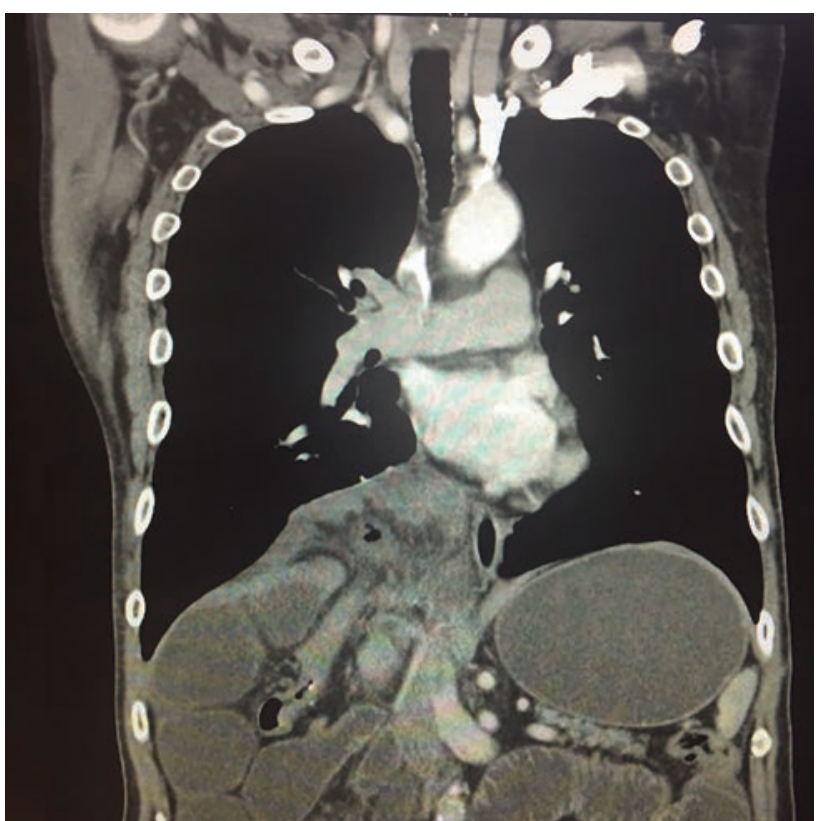

El paciente se intervino de forma urgente. Se evidenció una herniación de la anastomosis ileocólica previa con signos de sufrimiento. Se le realizó una laparotomía exploradora con la reparación del orificio mediante una sutura discontinua reabsorbible (Figura 3). El paciente fue dado de alta al quinto día postoperatorio sin incidencias y se encuentra en seguimiento en la actualidad.

Figura 3. Imagen intraoperatoria donde se reconoció el defecto diafragmático.

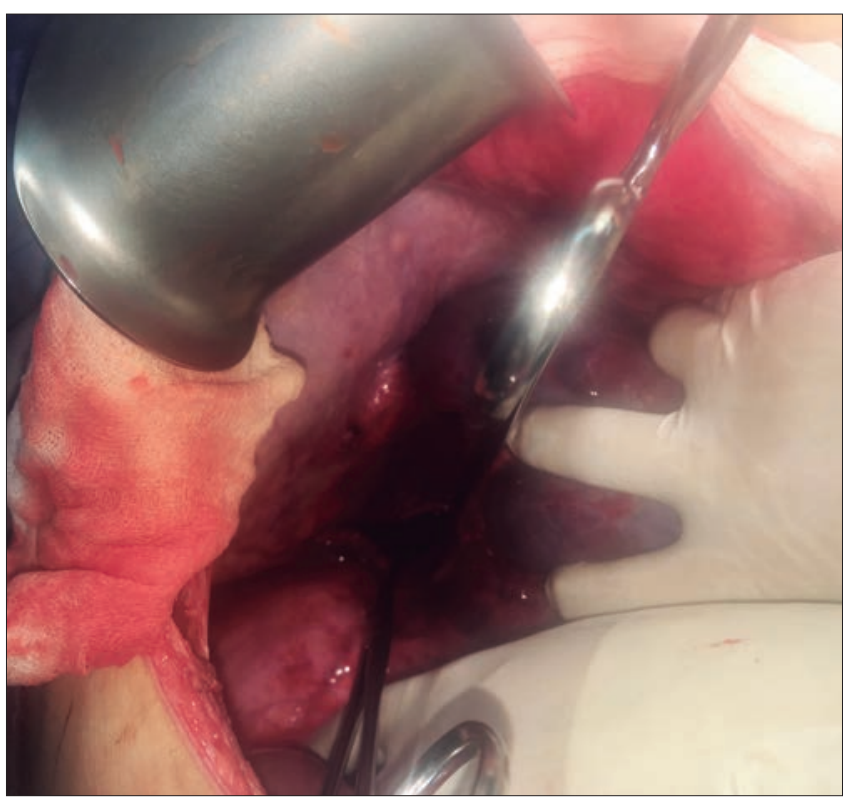

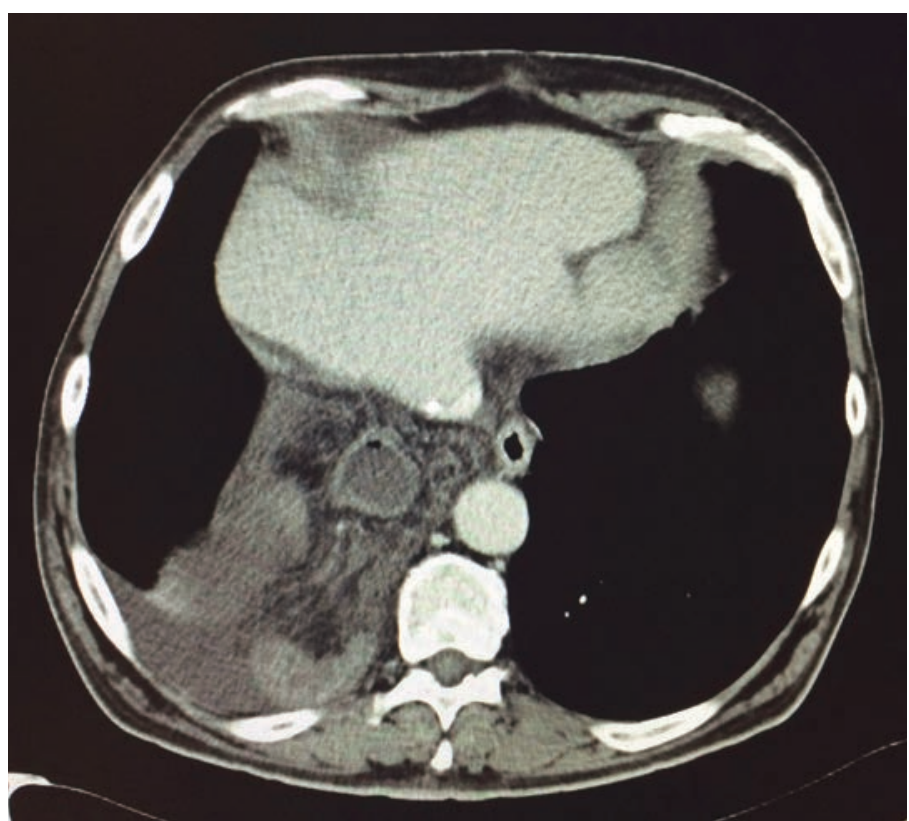

\section{Discusión}

Se debe sospechar de forma sistemática una ruptura de diafragma ante cualquier traumatismo torácico o abdominal, porque se producirá una discontinuidad que comunica la cavidad abdominal con la torácica. ${ }^{2}$ Entonces, la tracción producida por la presión negativa de la cavidad torácica sobre las vísceras abdominales hará que se introduzcan a través del desgarro, de manera inmediata o en el plazo de unos días. ${ }^{1,3}$

En la mayoría de los casos, los pacientes son asintomáticos o presentan síntomas inespecíficos (disnea, inmovilidad de un hemidiafragma, ruidos hidroaéreos intratorácicos). ${ }^{4}$ Las pruebas de imagen pueden no mostrar la ruptura, siendo diagnosticadas en un 30-50\% de los casos.

Incluso, hasta un $10-30 \%$ de las lesiones no se identifican en la fase aguda, pues se trata de pequeñas lesiones que van agrandándose con el paso del tiempo, siendo diagnosticadas años después de manera casual o por molestias inespecíficas. ${ }^{2}$

En las pruebas de imagen se visualizan las vísceras ascendidas, pero es difícil que se identifique la ruptura. En la radiografía de tórax suele aparecer una imagen aérea en la base izquierda, que rechaza el pulmón hacia arriba y el mediastino hacia la derecha. ${ }^{5}$ Por esto, debe hacerse el diagnóstico diferencial con un hemoneumotórax. La TAC constituye la prueba de referencia para las lesiones tanto agudas como antiguas, porque permite visualizar el defecto diafragmático y las vísceras ascendidas. ${ }^{1,4}$ 
Una vez diagnosticada, constituye una indicación para el tratamiento quirúrgico de urgencia. ${ }^{5}$ En las lesiones operadas de forma urgente, la mejor vía de abordaje es la laparotomía, pues permite el tratamiento de la ruptura diafragmática y de las vísceras abdominales. ${ }^{3}$

Durante la preparación, la colocación de una sonda nasogástrica que descomprima el estómago puede mejorar la función respiratoria. Se prefiere una incisión media supraumbilical a una incisión subcostal. ${ }^{4}$ Mediante las maniobras de tracción suaves, se reducen y se exploran las vísceras ascendidas, así como el resto de la cavidad, descartando la existencia de lesiones asociadas. En el caso de una estrangulación, debe plantearse la viabilidad del segmento afecto. A continuación, se liberará el perímetro de la rotura diafragmática, y lo habitual será realizar una sutura de borde a borde, con hilo no reabsorbible., ${ }^{2,5}$

\section{Conclusión}

La hernia diafragmática constituye una forma poco frecuente de afección y se necesita un índice elevado de sospecha para su diagnóstico.

El diagnóstico se facilita mediante el uso de la tomografía computarizada y la resolución quirúrgica precoz tiene un buen pronóstico.
El tratamiento es quirúrgico en la fase aguda y el abordaje recomendado es la laparotomía, debido a la alta asociación con las lesiones de otros órganos abdominales.

Conflicto de intereses. Los autores declaran no tener ningún conflicto de intereses.

\section{Referencias}

1. Özgüç H, Akköse S, Sen G, Bulut M, Kaya E. Factors affecting mortality and morbidity after traumatic diaphragmatic injury. Surg Today 2007; 37: 1042-1046.

2. Meyers BF, Mc Cabe CJ. Traumatic diaphragmatic hernia, occult marker of serious injury. Annals of Surgery 1993; 218: 783-790.

3. Lerner CA, Dang H, Kutilek RA. Strangulated traumatic diaphragmatic hernia simulating a subphrenic abcess. J Emerg Med 1997; 15: 849-853.

4. Gómez G, Fibla Alfara J, Farina Ríos C, Carvajal Carrasco A, Penagos JC, Estrada Saló G, León González C. Lesión diafragmática traumática. Revisión de 8 casos. Arch Bronconeumol 2002; 38: 455-457.

5. Rashid F, Chakrabarty MM, Singh R, Iftikhar SY. A review of delayed presentation of diaphragmatic rupture. World J Emerg Surg 2009; 4: 32 . 